\title{
Advancing salt marsh restoration for coastal resilience: a learning exchange
}

\author{
Nicole Maher (D) C Camilo Salazar • Alexa Fournier
}

Received: 12 March 2021 / Accepted: 5 October 2021 / Published online: 28 October 2021

(C) The Author(s) 2021

\begin{abstract}
A multidisciplinary group of salt marsh professionals from Maine to Virginia participated in a collaborative learning exchange to improve restoration for the overall health and resilience of coastal wetlands. This was an unprecedented forum through which participants representing different geographies, backgrounds, and roles in salt marsh management were able to share and learn from one another to develop the best available restoration methods for onthe-ground projects that address multiple benefits. By including mosquito control agencies, restoration practitioners, regulatory agencies, academic researchers, and conservation organizations in the learning exchange, we developed an understanding and acceptance of different approaches. Regulators learned
\end{abstract}

Supplementary Information The online version contains supplementary material available at https://doi.org/10.1007/ s11273-021-09841-5.

N. Maher $(\bowtie)$

The Nature Conservancy in New York,

Cold Spring Harbor, NY, USA

e-mail: nmaher@tnc.org

C. Salazar

Suffolk County Department of Economic Development and Planning, Suffolk County, NY, USA

\section{A. Fournier}

Division of Marine Resources, New York State

Department of Environmental Conservation, Kings Park,

NY, USA about project ideas and contributed to project designs in early development stages. Collaborating while engaged in on-the ground projects enabled participants to implement lessons learned in real time. Field trips to restoration sites at different stages of development allowed a greater and more fluid exchange of ideas and practical implementation advice. Practitioners leveraged resources and developed new collaborations. Lessons learned and shared through this faster and more flexible forum will inform the design, implementation, and monitoring of restoration projects across the region and improve overall marsh health and resilience in the face of climate change. Learning exchanges like this should be used more frequently to improve the efficiency and effectiveness of coastal restoration particularly when there is a windfall of cash and a short window of opportunity such as with post-disaster federal spending.

Keywords Learning exchange $\cdot$ Salt marsh restoration - Coastal resilience - Minga . Field trips · Climate change

\section{Introduction}

Tidal wetlands are extremely valuable for the multiple benefits they provide to both natural and human communities (UNEP 2006), but they are facing grave 
risks: a large fraction has been lost to date (e.g. Basso et al. 2015; CEA 2015) and climate and habitat projections suggest further losses in the future (e.g. NYSERDA 2018) unless we engage in restoration at scale. This urgent situation calls for restoration approaches that are more effective and efficient than the project by project model and traditional learning methods (e.g. annual conference presentations, peerreviewed publications, individual projects conducted and evaluated locally). Collaborative Learning exchanges (e.g. Paolisso et al. 2019; Feurt 2008) provide measurable benefits that are more responsive to the needs of diverse stakeholders and extend benefits beyond the reach of individual projects. A restoration effort after Hurricane Sandy provides a good example of a successful regional collaborative learning exchange. After the storm roared up the east coast of the United States in October 2012, previously scarce federal dollars for restoration flowed for projects across the states most heavily impacted by the storm. The US Fish and Wildlife Service (USFWS) initiated 14 coastal marsh restoration projects on federal lands (Babson et al. 2020). The U.S. Department of the Interior's (DOI) Hurricane Sandy Coastal Resiliency Competitive Grant Program (HSCR) administered by the National Fish and Wildlife Foundation (NFWF), supported 15 additional marsh restoration projects led by non-federal partners including state and local governments, tribes, nonprofits, and universities (Dwyer et al. n.d.). All Sandy-funded projects were to be initiated and completed within four to five short years.

A collaboration among the Suffolk County Department of Economic Development and Planning, Suffolk County Parks, and Suffolk County Vector Control in NY, jointly referred to as Suffolk County, received one of these HSCR NFWF grants to implement Integrated Marsh Management (IMM) as described in Rochlin et al. (2012). The funds were awarded to promote coastal resilience by restoring multiple functions and environmental benefits to over 200 acres of tidal marsh on the south shore of Suffolk County and build the capacity to eventually rehabilitate 1500 acres. The County's multifaceted IMM approach strives to improve tidal hydrology, remediate the historic mosquito grid ditch network, enhance processes for marsh accretion and resilience to sea level rise, promote healthy native vegetation, provide natural control of the invasive common reed,
Phragmites australis, and promote natural biological control of mosquito larvae. All Suffolk County restoration sites implemented through this project are part of the South Shore Estuary Reserve: Suffolk County Gardiner Park West (71 acres), Suffolk County Gardiner Park East (26 acres), West Sayville Marsh (113 acres), and Timber Point Marsh (51 acres).

In this paper, we share the Methods of our salt marsh restoration learning exchange. We describe four types of Benefits of the learning exchange: Achieving Multiple Benefits, Engaging Regulators, Learning in Real Time, Practical Knowledge Exchange in the Field. We highlight two types of Outcomes: specific outcomes for implementation of the Suffolk County restoration projects (Suffolk County Project Implementation), and more general outcomes for building social capital among participants (Professional Relationships and New Collaborations). We put this learning exchange in the context of the state of the world (Considerations and Questions for the Future). Finally, we stress the urgent need for successful restoration and encourage more flexible and expedient restoration learning collaborations like this one. We believe they are essential to generate the transformation necessary to meet the needs of our changing planet (Discussions and Conclusions).

\section{Methods of the learning exchange}

In addition to active restoration, Suffolk County's project included a learning exchange among salt marsh restoration experts across the Sandy-impacted region (from VA-ME) (Maher 2018). This learning exchange, assembled and led by The Nature Conservancy in NY (TNC), was called the Regional Technical Workgroup (RTW). The RTW was a forum for practitioners to discuss the best available restoration methods and share lessons learned to improve the success of coastal wetland restoration projects both within Suffolk County and across the larger region.

When we initiated this learning exchange, we were unaware of the established Collaborative Learning structure described by Daniels and Walker (2001) and demonstrated by Feurt (2008). We inadvertently used some of the principles they describe. Future efforts will benefit from following their established protocols more closely. 
Approximately 50 participants from the Sandyimpacted region comprised a multidisciplinary group of salt marsh professionals including the Principal Investigators of the post-Sandy funded marsh restoration projects, restoration practitioners, mosquito control specialists, natural resource managers, regulators, academic researchers, and conservation scientists. Notably, the learning exchange also included agency representatives from Federal, state, county, and local municipalities with expertise in conducting and evaluating restoration projects. Active participation grew and shrank over the course of the 2-year timeline as individuals' availability changed and as their expertise and interest intersected with the objectives of each scheduled meeting and field trip.

The learning exchange was conducted through both traditional in-person and remote meetings as well as field trips to restoration sites over the course of 2 years. In-person meetings were held at the start (fall 2016) and end (fall 2018), two webinar meetings were held in the middle (winter 2017 and summer 2018). Ten days of field trips scheduled throughout the project timeline visited a total of 20 marsh sites across the region.

Participants contributed their experience and shared their projects for review during the meetings and field trips. Projects included those in early stages of development, currently underway, and various ages post completion. Projects funded under the post-Sandy funding streams were emphasized. Suffolk County shared their initial restoration designs based on their holistic IMM approach for rigorous evaluation and peer review through the learning exchange to ensure implementation of the best available methods to achieve multiple benefits and coastal resilience. Arguably, the most productive meetings were designed as "field trips" at restoration project sites where conversations were more free form. Field trips were hosted at the Suffolk County sites pre-restoration (Fig. 1) and at partner sites both pre-restoration and at different stages post-restoration (Online Resource 1). Additional photographs of field visits to the Suffolk County sites post-restoration are also available in Online Resource 1.

During meetings, we shared our different perspectives, sometimes without directly addressing inherent disagreements. We never tried to reach consensus or informed consent. Perhaps this was because of the acknowledgement that every site is unique; perhaps it was because at different sites project leads prioritized different measures of success. Participants were open and generous in sharing lessons learned from across the region at sites that were similar and others that were quite dissimilar. Hearing perspectives from different regions helped advance our thinking about the marshes in our own locales.

We distributed presentations, meeting notes, meeting recordings, referenced papers and reports, field trip notes, and photographs after each meeting and stored relevant information on a shared online folder for easy access by participants. Members used this online folder as a repository for other resources that they wanted to share. Discussions focused primarily on two types of restoration approaches: restoring hydrology and restoring elevation. A final report (Maher 2018) captured the motivation of the learning exchange and bulleted lists of lessons learned by category.

\section{Benefits of the learning exchange}

Incorporating a learning exchange into an on-theground restoration project provided an efficient platform for the continuous discussion of best practices and an opportunity to implement those recommendations in real time. Some of the benefits and lessons learned through this experience are described below under the headings: Achieving Multiple Benefits, Engaging Regulators, Learning in Real Time, and Practical Knowledge Exchange in the Field.

Achieving multiple benefits: exploring runnels as an example

Restoration projects are typically designed locally to meet the goals of whichever agency is leading the effort. An avian conservation group may prioritize restoration of habitat for obligate salt marsh nesting birds; a sporting organization for specific species of waterfowl; a municipality for flood risk reduction for a coastal community; a vector control agency for mosquito control. Restoration can also be optimized to promote long term resilience by facilitating marsh migration. However, when designed purposefully, restoration of coastal marshes can achieve multiple benefits for wildlife, coastal communities, and coastal economies (Rochlin et al. 2012; Wigand et al. 2015; Wolfe 1996, 2005). 


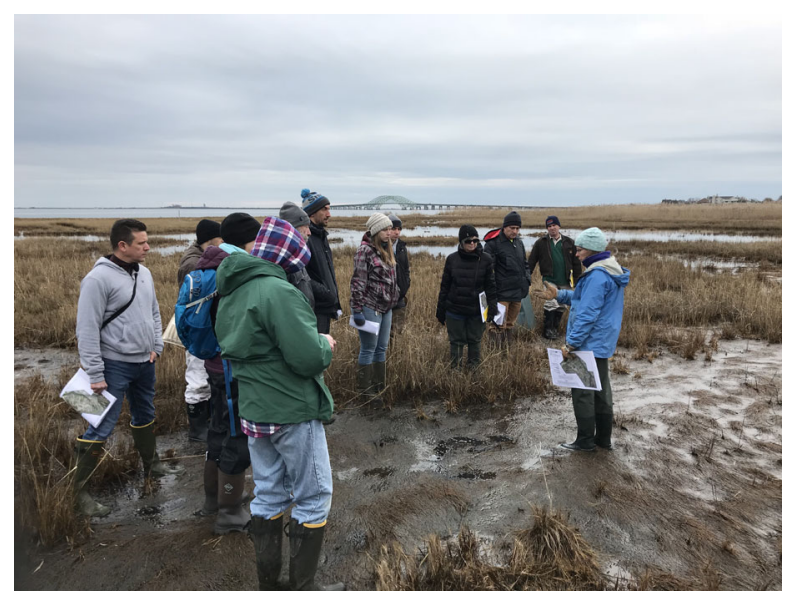

Fig. 1 Field trip to Suffolk County's Gardiner County Park East restoration site pre-restoration (11/18/18). Changes can happen quickly - even over one growing season. The group is standing in a patch of typical "high marsh" grasses (Spartina patens and Distichlis spicata) that is soggy with shallow standing water at

There is growing recognition of the value of integrating science and management activities to achieve multiple benefits (e.g. Dale and Huslman 1990; Dale and Knight 2008, 2012; Wolfe 2005). Dale and Knight (2008) specifically call this out as a knowledge gap that requires interdisciplinary collaboration. Similarly, Wolfe (2005) identifies communication among researchers, mosquito control managers, and regulators as a missing link. Furthermore, Dale and Hulsman (1990) make it clear that the multidisciplinary approach necessary to manage complex coastal ecosystems is often beyond the resources of individual mosquito control districts' capacity to achieve. Our learning exchange provided an opportunity for a multidisciplinary group to collaborate and fill these critical gaps to identify the best available restoration methods to meet multi-stakeholder needs and address multiple benefits (e.g. mosquito control, coastal resilience, flood risk reduction, habitat protection for threatened species, long term habitat sustainability).

Mosquito control agencies offered unique experiences and expertise in this learning exchange, including long term familiarity with the sites they manage through different weather patterns and seasons. Although their goals are more holistic now, historically their primary goal in saltmarsh management was to reduce the production of mosquitoes that are vectors of disease. This single-minded approach including low tide from poor drainage. Notice the Robert Moses Causeway bridge in the background as a marker. A photo of this same spot two growing seasons after restoration is shown in Fig. 7. (N. Maher @TNC)

grid ditching and chemical control was destructive to marsh ecosystems (Hulsman et al. 1989; Wolfe 2005; Dale and Knight 2008). A growing appreciation for the value of marsh ecosystems inspired development of alternatives to these earlier destructive methods (Hulsman et al. 1989; Wolfe 2005; Meredith and Lesser 2007). More recent approaches include draining water from the surface of the marsh (source reduction) and enhancing water flow and fish access to depressions on the marsh surface that are ideal breeding grounds for salt marsh mosquitoes. This allows native killifish species to consume larvae before they become flying, biting, adults (biological control).

Runnels are a tool intentionally developed by mosquito control practitioners in Australia to facilitate biological control of mosquitoes while maintaining or at least minimizing impacts to natural marsh function (Hulsman et al. 1989). Runnels, as codified in Australia, are shallow "spoon-shaped" channels that are at least three times as wide as they are deep positioned to drain standing water from low spots on the marsh surface and prevent larval development in those areas (Hulsman et al. 1989).

In contrast to Australia, the US uses a more informal definition and approach to runnels and there are morphological differences between the runnels implemented for mosquito control in the US and Australia. In the US, runnels for mosquito control 
(positioned for either source reduction or biological control) are always shallower than drainage ditches or creeks, but they are not always wider than they are deep. For example, in Suffolk County, NY, runnels are designed to serve the needs of the microtidal regime (tidal amplitude on the south shore of Suffolk County is only $21-33 \mathrm{~cm}$ ). Accordingly, the dimensions of runnels here average $30.5 \mathrm{~cm}$ wide by $30.5 \mathrm{~cm}$ deep. They can be dug by hand with a shovel ( $23 \mathrm{~cm}$ blade), or mechanically using an excavator with a $70 \mathrm{~cm}$ bucket rotated $45^{\circ}$, a $30.5 \mathrm{~cm}$ bucket, or a blade (Fig. 2). Most runnels are connected to tidal channels and some are connected to permanent micropools that offer fish habitat on the marsh surface. Figure 3 shows an example of a micropool and runnel installed at Suffolk County Gardiner Park West site less than a

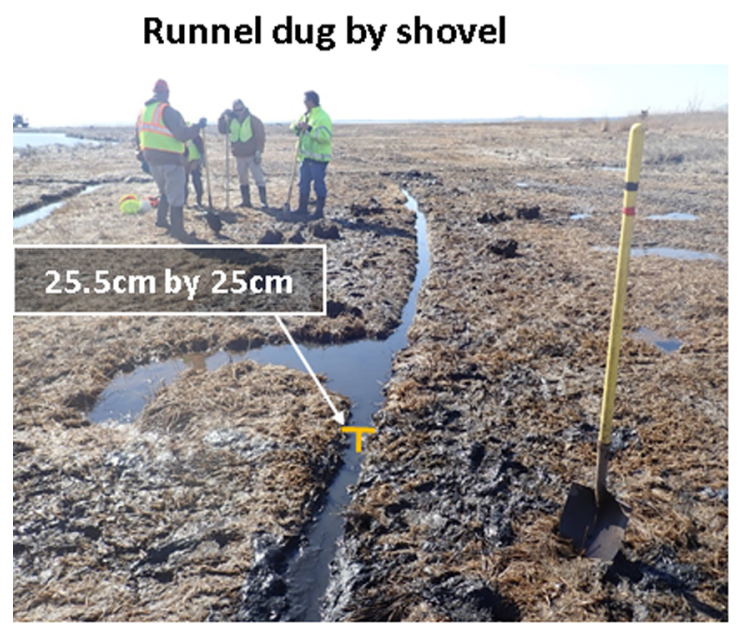

\section{Runnels dug by excavator with $30.5 \mathrm{~cm}$ bucket}

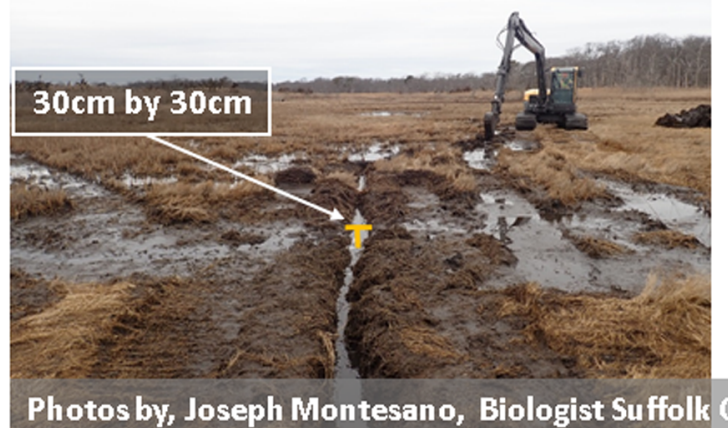

Photos by, Joseph Montesano, Biologist Suffolk County DPW year after implementation. The average dimensions of micropools as implemented in these Suffolk County projects are $3 \mathrm{~m} \times 3 \mathrm{~m} \times 0.6 \mathrm{~m}$. In Delaware, USA, Meredith et al. (1985) and Meredith and Lesser (2007) describe shallow channels called "sill ditches" to remove water from shallow surface water larval habitats and "radial ditches" to provide fish access between permanent ponds and outlying larval habitats. These shallow sill and radial ditches are sometimes informally called "runnels" in the US even though they do not fit the intent or definition of runnels as created in Australia.

Runnels are a good opportunity for collaboration among diverse stakeholders and to achieve multiple benefits, but there are some terminology hurdles to overcome. Independently, salt marsh ecologists in

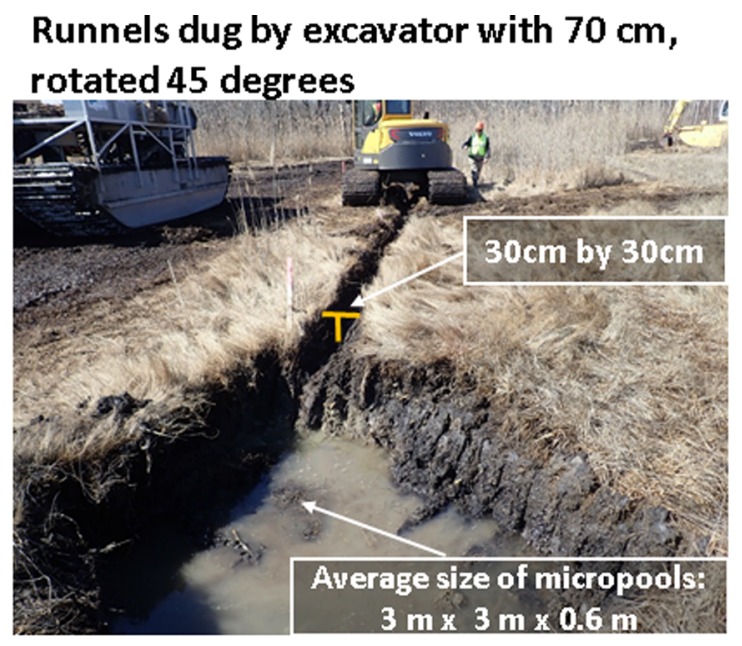

\section{Runnels dug by excavator blade}

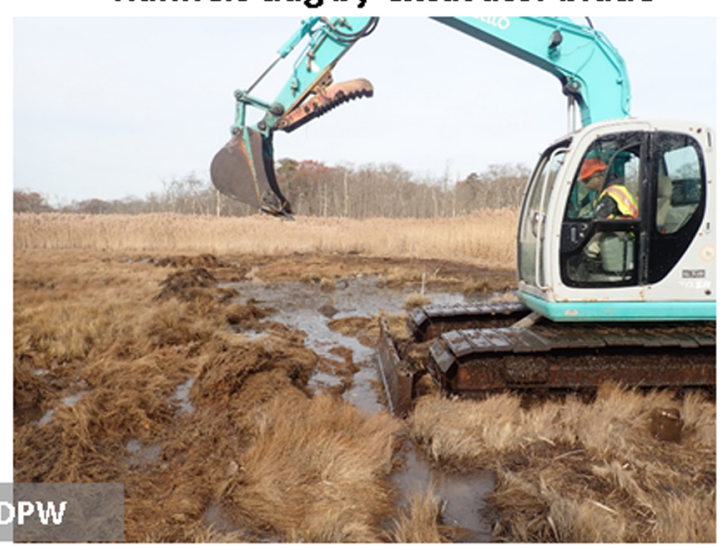

Fig. 2 Runnel implementation at Suffolk County's Gardiner County Park West restoration site: runnels were built by shovel ( $\sim 23 \mathrm{~cm}$ blade), excavator $\left(70 \mathrm{~cm}\right.$ bucket, rotated $45^{\circ}$ ), excavator (30.5 cm bucket), and excavator with a blade. Average runnel dimensions $30.5 \times 30.5 \mathrm{~cm}$. (J. Montesano, SC Vector Control) 
Fig. 3 Micropool and runnel in upper part of high marsh habitat near the invasive Phragmites line at Suffolk County Gardiner Park West less than one-year post-restoration (03/08/21). Dimensions of runnels installed here are $30.5 \times$ $30.5 \mathrm{~cm}$; dimensions of micropools are $3 \mathrm{~m} \times 3 \mathrm{~m} \times 0.6 \mathrm{~m} .(\mathrm{N}$. Maher@TNC)

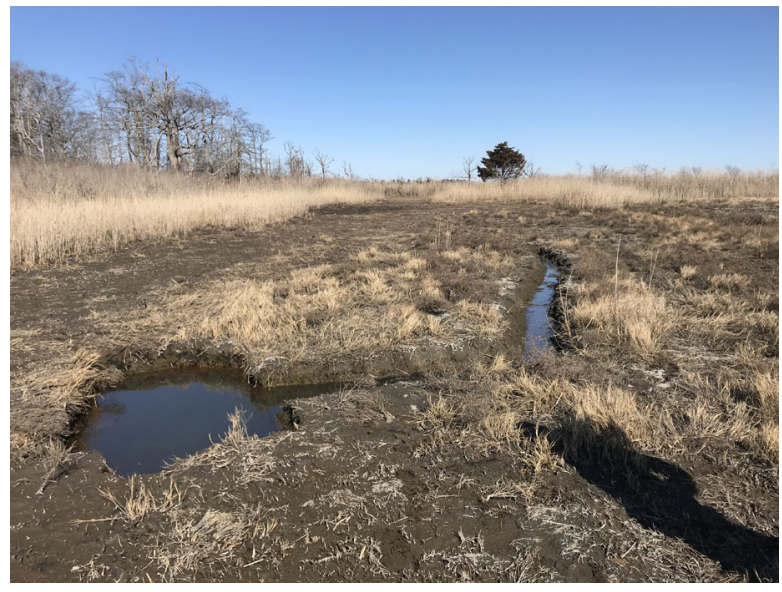

runnels was for source reduction or biological control of mosquito larvae (water and fauna). This compares to the later marsh ecology application which focused on promoting revegetation (water and flora). Recently, the mosquito control use of runnels also includes the purpose of draining shallow, improperly impounded water created by parallel ditch levees to allow flushing and vegetative recovery (R. Wolfe, pers. com.), similar to the intentions of marsh ecologists. For these reasons, being explicit about our intentions for runnels and how they implemented is important. There is a valuable opportunity to engage across these complementary disciplines (mosquito control and marsh ecology) to develop minimally invasive restoration approaches that achieve multiple benefits. Each group has a lot to gain from the other to inform effective restoration and resource management. By engaging representatives of these different disciplines simultaneously, and sharing our diverse experiences, challenges, and lessons learned we can appreciate each others' perspectives and tools in the field. However, there is not a universal understanding for the purpose and implementation of what we both call runnels. This remains an example of where we have more to learn from each other as we learn how to manage marshes to achieve multiple benefits and how marshes respond to these restoration techniques. Dale and Knight (2008) emphasize that mosquito and wetland management communities need to communicate and collaborate to simultaneously protect both wetland and human health. We argue that multidisciplinary learning exchanges, like we demonstrate here, are more expedient and potentially more effective than attending each others' professional meetings to glean similar 
knowledge, open lines of communication, and develop an understanding of our complimentary marsh management and its critical role in climate resilience.

Engaging regulators: building a mutually beneficial relationship

The regulatory approval process for any wetland restoration project is a long and complicated endeavor. There are environmental protection regulations that must be followed under federal, state, and local governments, and grant-funded projects may have additional requirements for compliance. For these reasons, there can be friction between those hoping to implement restoration work and the regulatory authorities they perceive to be standing in their way. This learning exchange provided a platform for ongoing, open communication between restoration practitioners and regulatory staff. Regulators were able to contribute to design ideas during early project development rather than reacting to permit requests. It was crucial to have regulators on the front lines and actively engaged so they were free to contribute insights and design improvements before there had been investment in an alternative project approach. Regulatory staff also learned from practitioners why a particular strategy was more likely to succeed, or why a commonly held permitting standard might not be appropriate for a particular project.

Although it may feel like they are in opposing positions during the permitting process, environmental regulators and restoration practitioners seek a common outcome: a healthy, productive, and sustainable ecosystem. Both sides come with inherent advantages. Regulators see a large number of projects over time and can often predict where issues may arise based on past experience. Practitioners, meanwhile, may be more knowledgeable about new restoration techniques and promising experimental methods. This learning exchange gave regulators a chance to see novel restoration techniques in the field beyond their home states, broadening their understanding of current restoration science while increasing their comfort in the feasibility of these methods.

Learning in real time

This learning exchange provided real time peer review for all participants to improve their own restoration efforts and maximize their likelihood of success. It was a tangible opportunity for interdisciplinary capacity building, providing opportunities for local project managers and regulatory staff to engage with restoration experts and research scientists. This approach also provided the opportunity for all involved to stay current on the latest thinking in restoration science. Discussions included critical evaluation of restoration site selection, design, implementation, monitoring, and adaptive management. Mosquito control specialists, as well as local regulators and managers, bring valuable experience to these conversations but are frequently unable to participate in national scientific and restoration conferences that require travel across state lines. Local learning exchanges can be a critical opportunity for them to engage with their peers in other sectors.

The learning exchange also connected practitioners across a larger geography than is common for development of individual projects. Participants represented active projects from Maine to Virginia which brought geographically diverse experiences and perspectives. As a result, when they shared lessons learned from their individual projects, those lessons influenced multiple projects and practitioners from across the entire region.

\section{Practical knowledge exchange in the field}

Field trips to restoration sites at different stages of implementation were exceptionally productive. It was invaluable to see the sites firsthand, develop a shared perspective, compare site conditions, ask questions, and discuss alternatives while assessing a site in real time. These onsite meetings allowed a more fluid exchange of ideas including implementation advice and operational details that never make it into written reports, publications, or presentations. These crucial details play a large role in executing successful projects on the ground. In this informal setting, participants freely discussed insights gained, pros and cons of different types of equipment, challenges faced when working with contractors, unanticipated modifications necessitated by site conditions, adaptive management tactics, and other lessons learned. Field visits were a safe space to share lessons learned from failures and false starts without judgement by regulators or funders. We all recognized that there is no agreed upon guidance for deciding which treatments 
are best for which sites because marsh restoration is not prescriptive; we need to experiment, measure, learn and share.

Meetings conducted on restoration sites enabled participants to understand the full context of those projects. Although there are many similarities among degraded salt marshes (often resulting from widespread historic practices such as grid ditching) each site is unique and warrants careful consideration of local conditions. Habitat heterogeneity necessitates customized restoration designs to meet site specific needs and stakeholder objectives. Field trips provided insight into local conditions and a more realistic view of potential restoration practices.

All field trips occurred before Suffolk County finalized and implemented its restoration plans, and the field visits helped to refine many of the designs' technical details. The field trip to a collection of restoration sites in Rhode Island (RI) led by Wenley Ferguson, Director of Habitat Restoration with Save the Bay (https://www.savebay.org) was especially enlightening. Suffolk County was considering if runnels were the best way to address improperly impounded water on the marsh surface and if so, how and where to implement them. Practitioners in RI are restoration leaders in figuring out when, where, and exactly how to implement minimally invasive yet effective runnels to address improperly impounded water causing marsh subsidence (Ferguson 2016; Wigand et al. 2015).

Rhode Island presents a shining example of how conservation and mosquito control practitioners can work collaboratively to achieve multiple goals in their projects (W. Ferguson pers. com.). By visiting restoration sites in RI with similar site characteristics to those in Suffolk County (microtidal marshes with low sediment supply), we observed marsh response to runnel treatments of different ages implemented by Save the Bay, RI Department of Environmental Management Mosquito Abatement Coordination, and USFWS. We also learned how the experienced RI team evaluated a site in the planning stages by visiting one of their pre-restoration sites and engaging with them on the different considerations and alternatives under consideration for the strategic restoration plan. This helped Suffolk County better strategize the implementation of runnels on their own sites. See further discussion below.

\section{Outcomes}

Tangible outcomes of the learning exchange included improved restoration and monitoring plans for projects initiated by Suffolk County and the professional relationships formed and strengthened among the participants across the region. These different types of outcomes are described below in greater detail.

\section{Suffolk County project implementation}

Engagement with the learning exchange and observation of restoration sites with similar tidal regimes and restoration objectives informed strategic revision of Suffolk County's preliminary restoration designs. Many of the proposed recommendations were incorporated. This engagement reduced the risk of unanticipated results, promoted the efficient use of staff and funding resources, and smoothed the permitting process because the permit application was improved by real time, vigorous peer-review. Figure 4 shows a side-by-side comparison of the initial and final restoration designs for Suffolk County Gardiner Park East, as an illustration of the changes made across all Suffolk County sites implemented as part of their HSCR NFWF grant.

The first modification to Suffolk County's initial designs addressed the proposal for "naturalizing" or adding sinuosity to some linear mosquito ditches by cutting and repositioning sections of marsh peat along them to restore curvature. The primary motivation was to improve natural drainage and sediment deposition over the marsh while maintaining open channels for tidal exchange. A secondary aesthetic motivation was to remove artificial straight lines and restore sinuosity that more closely resembled natural tidal creeks. However, learning exchange participants thought the disturbance caused by ditch "naturalizing", in particular cutting and moving high quality peat and vegetation to add curves, would cause more harm than benefit. Regulators from the New York State Department of Environmental Conservation (NYSDEC) also objected to the intensive ditch reshaping originally proposed due to the possibility that the disturbance would cause contaminants within the sediments to be resuspended and reintroduced to biota. Instead, the Suffolk County team added sinuosity to the system with the purposeful placement of runnels (typically $30.5 \mathrm{~cm} \times 30.5 \mathrm{~cm}$ ) through low 


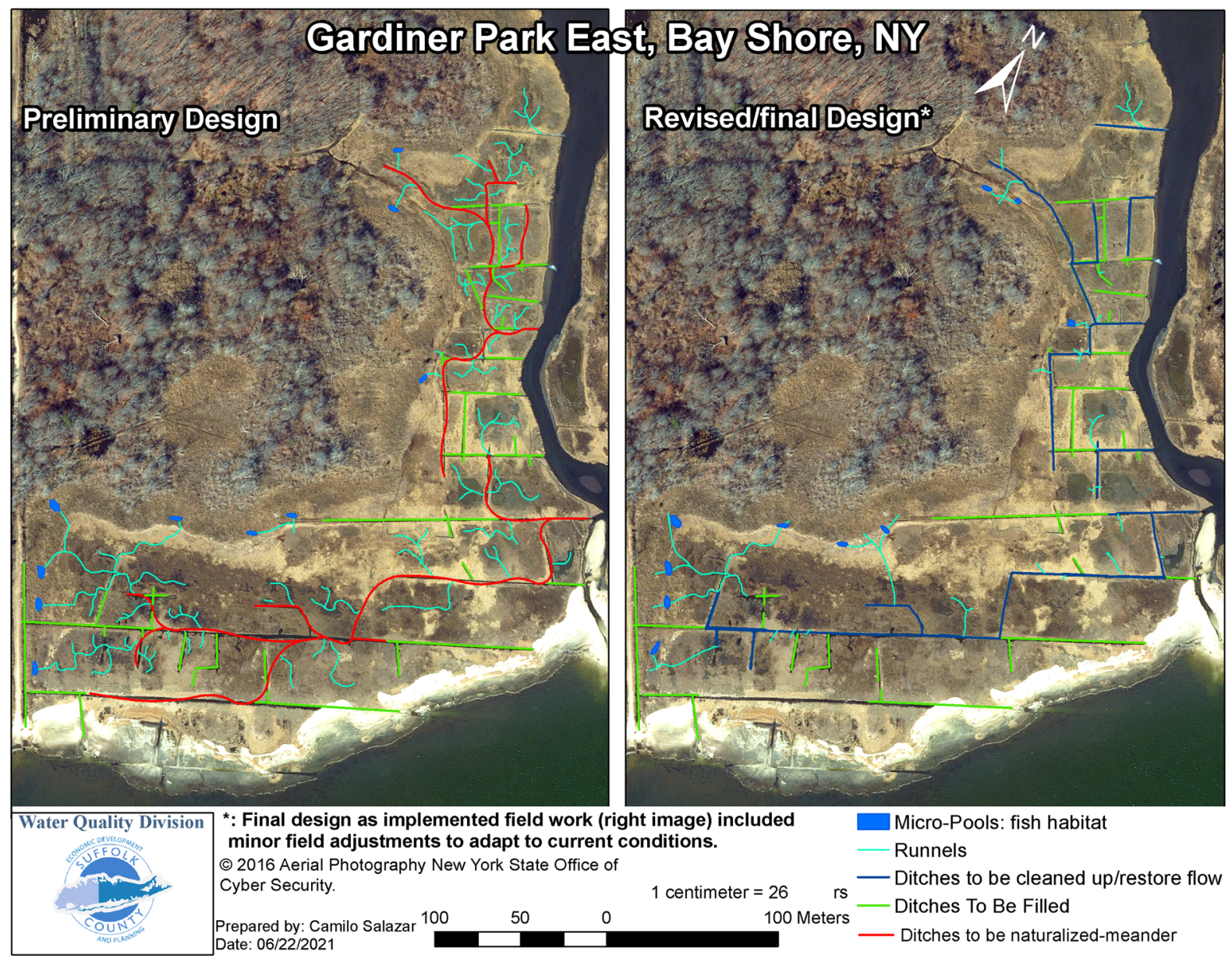

Fig. 4 Side by side maps of preliminary (left) and revised/final (right) restoration plans for Suffolk County's Gardiner Park East in Bayshore, NY. Meaningful changes incorporated from the learning exchange are displayed here. The ditches to be maintained as the primary tidal creeks were not "naturalized" to add sinuosity by cutting and repositioning peat. This was important to minimize disturbance and especially to avoid cutting healthy high marsh peat. The extraneous ditches were

areas and focused on strategic restoration of only those linear ditches with poor tidal connectivity. This allowed the County to avoid the extensive toxicity testing required by NYSDEC when moving or disturbing larger volumes of sediments.

A second improvement to the initial designs was partial modification of how the non-functioning linear mosquito ditches were retired. The team attempted to identify and restore natural 'tidesheds' in the project design so each system had a single main channel or primary ditch to accommodate the incoming and outgoing tide. Supplementary ditches were retired. filled with coir logs and natural peat from the site, but importantly, the slightly elevated levees along the sides of these ditches were not scraped down for use as fill. Instead, those areas were left to provide some elevation refuge for obligate salt marsh nesting birds. Fewer runnels were incorporated into the final designs, but those that were used were more strategically placed and used to add sinuosity. Multiple runnels drain into the same primary ditch to keep water flowing in and out

The concept of "ditch remediation" is to rebuild the peat that was once there by creating the conditions for fibrous organic material, sediment, and living roots to accumulate in the linear ditch (Burdick et al. 2020). When material reaches the appropriate elevation, plants naturally colonize through seedling or colonial growth. The approach demonstrated by Burdick et al. (2020) relies on harvesting salt hay from the surrounding marsh to place in ditches as a filter to trap material and start the peat building process. However, in marshes without this resource, managers may need to find substitutes for locally harvested salt hay. 
Preliminary designs for Suffolk County proposed utilizing a combination of coconut fiber logs (coir $\operatorname{logs}$ ) and material scraped from miniature levees along the sides of the linear ditches to fill the space up to the marsh surface.

The learning exchange advised experimentation with filling non-functioning ditches, provided there was sufficient drainage in the marsh, but it was best not to dig up stable marsh peat to do so, particularly along the slightly elevated ditch levees. They advised preserving elevation along the ditch edges to provide multiple habitat benefits, most notably for obligate salt marsh breeding birds such as the Saltmarsh Sparrow (Ammodramus caudacutus) known to inhabit these marshes on the south shore of Suffolk County (eBird.org). Saltmarsh Sparrows use the peat mound refugia for nesting and protection from high tides and return to the same marshes to breed in successive years, often nesting within a few meters of their previously successful nests (Benvenuti et al. 2018). Maintaining these refugia in place is important. Suffolk County recognized the ecological and economic value of maintaining intact peat and vegetation along these miniature levees. Leaving them intact preserved habitat and kept total excavation volume under the contaminant testing limits, thus reducing project costs. Because material for peat building was scarce at these sites, Suffolk County used intact coir logs and some natural peat excavated from runnel and micro-pool construction on site to fill ditches to the elevation of the marsh platform but did not scrape down material from the elevated ditch levees as originally proposed.

It is important to note that there was disagreement about the use of coir logs as fill. Many participants shared experiences with buoyant coir logs shifting out of position and causing complications on sites. One suggestion from the group was to open the coir logs and use the inner fibrous material to line the ditches in a manner similar to how Burdick et al. (2020) used mowed salt hayThe recommendation was to leave the coir fiber material exposed (not buried with peat) so that water could filter through and trap sediments to start the peat rebuilding process.

The learning exchange participants familiar with ditch remediation cautioned that the process of peat building was important and that it was not possible to skip to the endpoint by just putting peat on the top of coir filling. However, Suffolk County had concerns that leaving ditches partially filled could create new mosquito breeding habitat in these microtidal marshes. In previous IMM projects, Suffolk County maintained that retired ditches had to be filled flush with the surface of the marsh to prevent creation of new larval mosquito habitat (Rochlin et al. 2012).

Over two growing seasons since implementation, the coir logs have not caused the disruptions described by other learning exchange participants. A photograph of a ditch filled in this manner after 2 growing seasons is included in Online Resource 1. One possible explanation for the different response observed by Suffolk County is that the coir logs used in these projects were exposed to the elements for over 6 months and up to a year before deployment. This weathering may have made the coir material more stable when positioned, buried, and staked down in the ditches.

A third modification to the initial designs was the way runnels were strategically used to achieve three specific goals: to restore tidal hydrology and vegetation growth, to promote marsh migration and invasive species control, and to address mosquito abatement issues in breeding hot spots. Consistent with the marsh ecology use of the term, runnels were deliberately placed to restore drainage of shallow improperly impounded water that was preventing vegetation growth and elevation accretion on the marsh platform. Figure 5 shows surface hydrology before and after runnel implementation. Consistent with the mosquito control use of the term, runnels, and a small number of fish refuge micropools were created near the upper edges of the marsh where Suffolk County will address all three goals simultaneously (Fig. 3). Figure 6 shows the improved surface hydrology and vegetation recovery of the same location pictured in Fig. 1 two growing seasons post-restoration. Suffolk County is actively monitoring the function of these runnels (currently 1-2 years post implementation) to determine how well they are meeting their restoration and management goals.

Professional relationships and new collaborations

In addition to the restoration outcomes on the ground, other valuable outcomes of the learning exchange include the productive partnerships formed and strengthened through the process (Fig. 7). Practitioners across the region are now a ready resource to one 


\section{Before runnels}

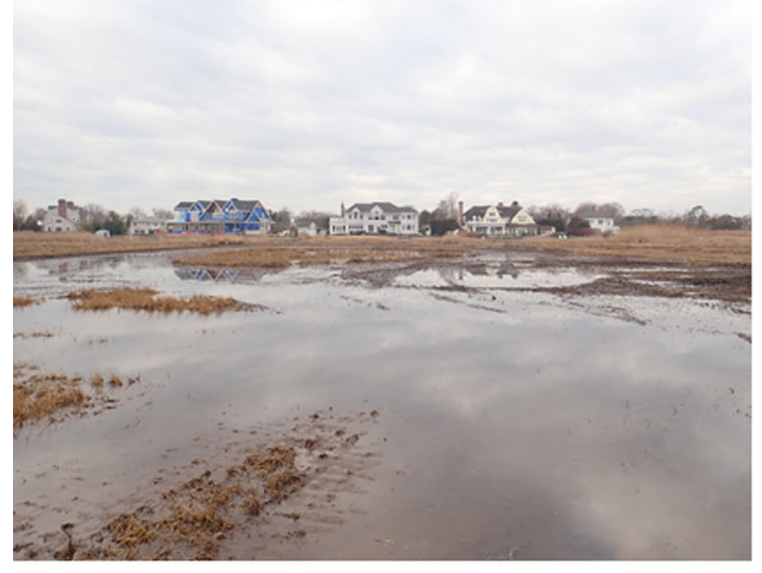

\section{Before runnels}

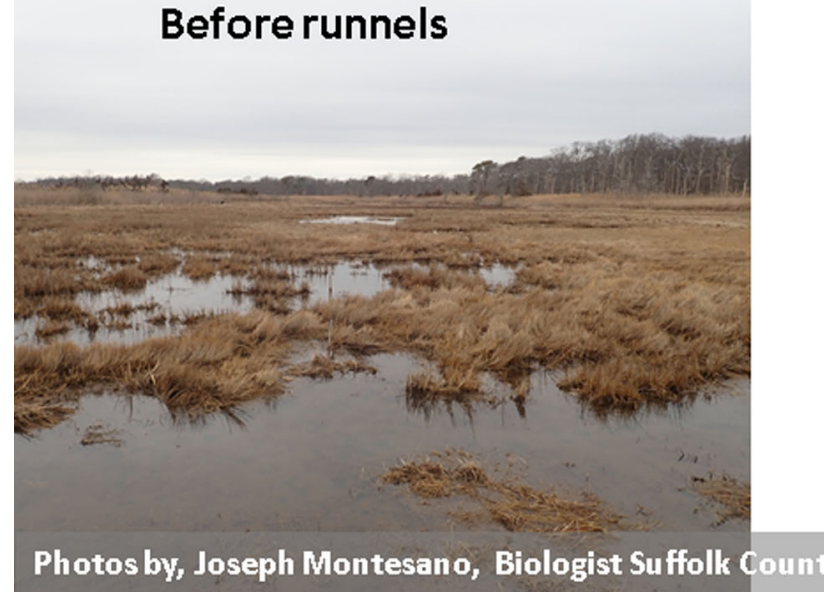

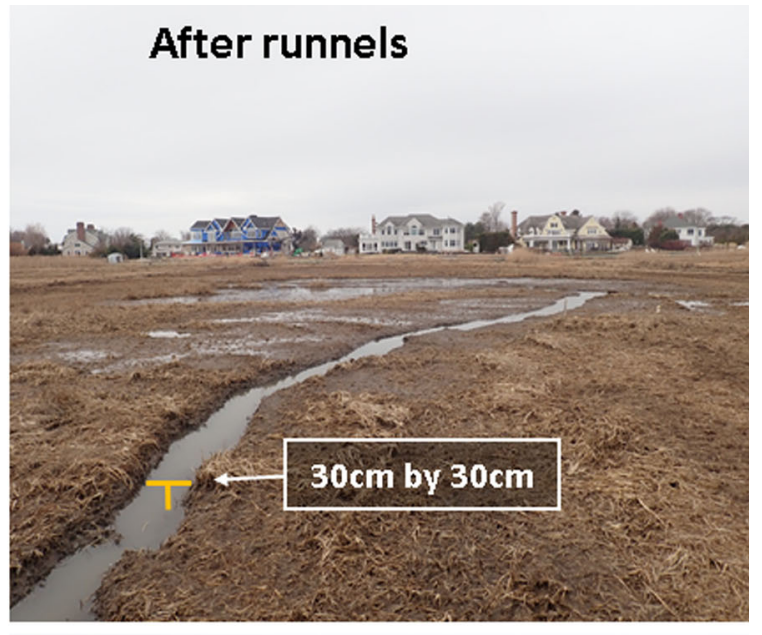

After runnels

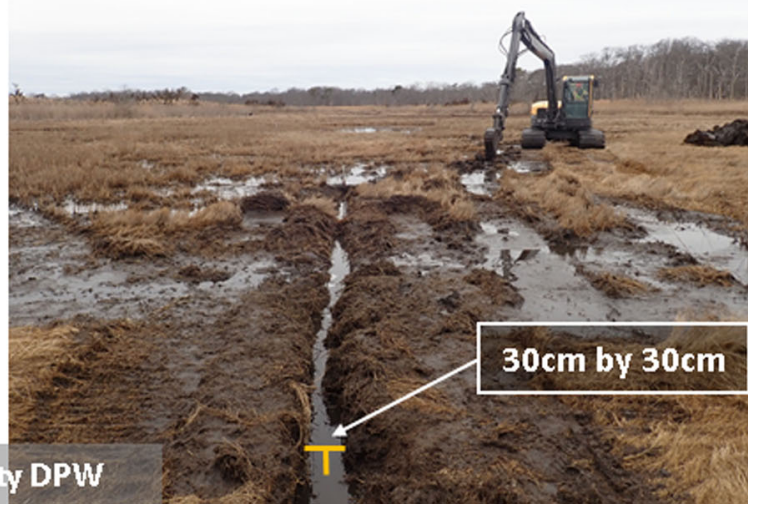

Fig. 5 Surface water before and after runnels $(30.5 \times 30.5 \mathrm{~cm})$ are cut on the Suffolk County Gardiner Park West site. (J. Montesano, SC Vector Control)

Fig. 6 Suffolk County Gardiner County Park East restoration site two growing seasons post-restoration (03/ $08 / 21$ ). This is the same location as featured in Fig. 1 pre-restoration. Notice the Robert Moses Causeway bridge in the background as a marker. There is some Spartina alterniflora, but the spot is dominated by Salicorna spp. (20 cm tall) indicating signs of recovery. (N. Maher @TNC)

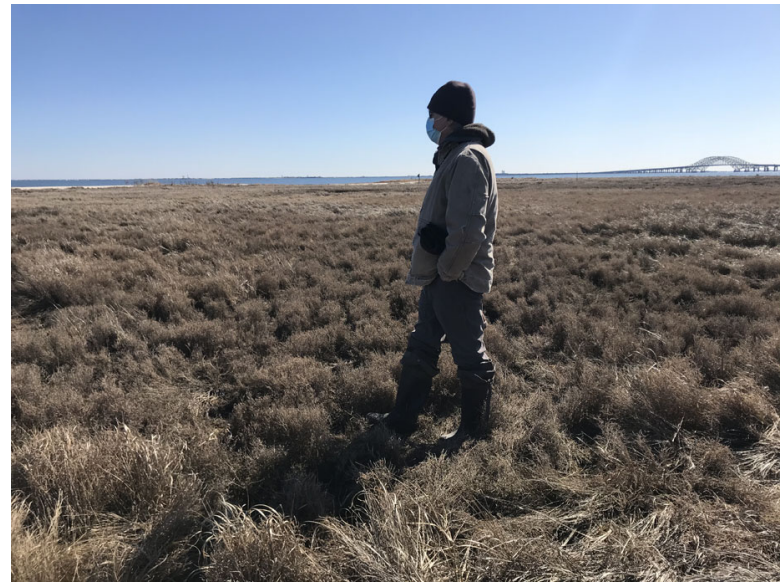




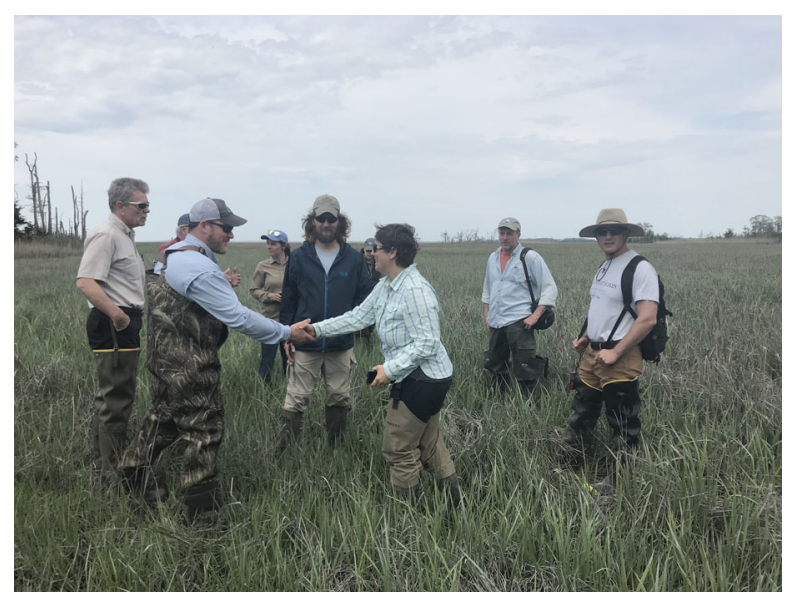

Fig. 7 Field visit to Cape May NWR in Cape May Court House, NJ. New introductions of partners. Jim Feaga, Ducks Unlimited meeting and shaking hands with Beth Watson, Academy of Natural Sciences of Drexel University (ANS). Ducks Unlimited

another and have the capacity to leverage resources for greater restoration and management outcomes. Although we didn't measure these valuable outcomes the way that Paolisso et al. (2019) did so skillfully, we have anecdotal evidence to this effect. There are too many examples of connections formed or strengthened through this learning exchange to be inclusive, but two examples are included here for illustrative purposes. The City of New York Department of Parks and Recreation (NYC Parks), The Nature Conservancy in New Jersey and the Partnership for the Delaware Estuary (PDE), now consult one another regarding techniques, materials and monitoring approaches for their respective living shoreline projects capitalizing on one another's resources and skills (Joshua Moody, Christopher Haight, and Adrianna Zito-Livingston pers. com.). Joshua Moody, Restoration Program Manager at the Partnership for the Delaware Estuary shared: "Having an open dialogue across regions regarding project development, implementation, and outcomes is a critical facet of restoration science, and these relationships are foundational in evaluating the transferability of specific goal-based restoration techniques." Additionally, Ducks Unlimited had not previously partnered with NYC Parks but now they have leveraged resources on what might be the first ever U.S. Fish and Wildlife Service \$1 Million Standard North American Wetland Conservation Act grant for southern New York including restoration had not previously engaged with ANS but following the learning exchange they connected on a number of projects including one at the John Heinz NWR in Philadelphia, PA. (N. Maher @ TNC)

sites from NYC and the eastern end of Suffolk County (Jim Feaga pers. com.).

In the time since our learning exchange concluded, many groups have expressed interest in convening learning exchanges across other geographies and areas of expertise and especially incorporating field trips into those learning exchanges. For example, USFWS and other partners recently convened conservation stakeholders throughout New Jersey (NJ) and Delaware (DE) to form a Salt Marsh Working Group. Communication and sharing lessons learned were top interests and purposes for the group. During initial working group meetings, this learning exchange was held up as a highly successful model that the NJ-DE group is hopeful to repeat, once interstate travel is again feasible (Adrianna Zito-Livingston and Mitch Hartley pers. com.). Working groups like this one are forming in several other locations in the northeast as well.

\section{Considerations and questions for the future}

The United Nations General Assembly declared 2021-2030 the "Decade on Ecosystem Restoration." This call to action recognizes the need to accelerate restoration of degraded ecosystems across the globe to get the world on track for a sustainable future. The declaration specifically calls out the importance of capacity building and cooperation including sharing 
experiences and best practices to build momentum and scale up ecosystem restoration to meet the needs of a changing climate.

Furthermore, there is renewed immediacy to restore Atlantic Coast salt marshes. The Saltmarsh Sparrow, an obligate salt marsh nesting bird endemic to this area, was recently recognized by the U.S. Fish and Wildlife Service as an "At Risk Species". While not placed on the list of federally threatened or endangered species, At Risk status indicates that federal and state agencies are placing special emphasis on conserving the sparrow's numbers. Without such intervention, population numbers are predicted to hit severely low levels by 2030 (Field et al. 2017). Since flooding of low elevation nests is one of the primary causes of decline, there is increasing emphasis to restore degraded marshes (Hartley and Weldon 2020). The best opportunity to do so is during the next 10 years while we are experiencing smaller tidal amplitudes in the current phase of the 18.6-year Metonic Cycle (Adamowicz et al. 2020). After that, the cycle switches to higher tidal ranges that will peak by about 2035.

But how do we organize restoration efforts on a scale large enough to make a difference? And how do we provide a quality assurance/quality control aspect to the endeavor? Building on the example of the learning paradigm described here, Adamowicz et al. (2020), describe a two-level approach-local and regional. The Salt Marsh Adaptation and Resiliency Teams (SMARTeams) model provides three support teams at the regional level: Design Review, Technical Support, and Training, Outreach, and Education. These teams assist local Field Teams-partnerships of landowners, NGOs, researchers, and others-who implement actual projects. Field Teams build within themselves economies of scale, enabling projects larger than any single partner could do alone. That economy of scale is used again in the regional level teams-providing services that could not be financed by individual Field Teams. Lessons learned are also conveyed through the SMARTeams in a comprehensive and rapid method-keeping all projects throughout the region connected in continual learning and improving.

\section{Discussion and conclusions}

Suffolk County had the foresight to include a regional interdisciplinary learning exchange (the RTW) as part of their HSCR NFWF grant. They recognized the immense value in learning from experts and projects across the region and wanted to make the most of the opportunity to implement restoration on $200+$ acres across Suffolk County by ensuring implementation of the best available methods. Importantly, they were open to hearing new ideas and having their assumptions challenged so the projects implemented had the greatest chance of success.

This learning exchange was an unprecedented assembly of marsh restoration practitioners across the Hurricane Sandy-impacted region. Because restoration science is still a developing and interdisciplinary field, this experience has identified the benefits of such platforms at the local and regional scale. Among the many take-away points from this exchange, we learned that diverse stakeholder groups, including mosquito control agencies, bring valuable experience to these conversations and should be included in marsh restoration and management discussions. Engaging regulators provided a platform for open communication and simultaneous learning for restoration practitioners and regulatory staff that both improved project design and streamlined the permitting process. It was also clear that real time learning and capacity building at the local level are paramount for getting restoration to scale. Conversations that occurred on field trips were especially valuable for conveying practical knowledge. Not all the recommendations from the learning exchange were incorporated into the projects implemented by Suffolk County, but the project designs were greatly improved by the recommendations that were adopted.

The effort proposed here (building capacity for efficient climate adaptation) is like a minga, a Quechua word from the Andean region which means equally benefiting collective work for all its participants. We propose that this type of engagement is a valuable model for our field. Even though it was difficult for participants to add another activity to their already full schedules, (especially up against the ambitious accelerated timelines instituted by funding agencies) the benefits of engagement were greater than the costs of doing so. 
We believe that this learning exchange has already had long-lasting effects on the Sandy-impacted northeast because it promoted better science and more successful individual restoration projects, connected practitioners from across the region, fostered new relationships, brought in new perspectives, and expanded the 'toolkit' for restoration project managers. We anticipate that successful learning exchanges like this will encourage additional regional collaborations and improve future salt marsh restoration projects. These benefits will provide better information to policy makers and funders to inform decisions about conservation, restoration, and management of salt marshes in the face of climate change. We still have much to learn from one another about how our marshes respond to restoration. The future of our salt marshes depends on our collaborations.

Acknowledgements This article was inspired by the Regional Technical Workgroup of saltmarsh restoration practitioners funded by NFWF grant funded project: Wetland Restoration in Suffolk County (NY) project ID 43006. N. Maher is grateful for the generous support of the William E. \& Maude S. Pritchard Charitable Trust. The findings and conclusions in this article are those of the author(s) and do not necessarily represent the views of Suffolk County. Dominick Ninivaggi, former Superintendent at Suffolk County (NY) Vector Control, played an instrumental role in steering Suffolk County's mosquito program towards more holistic marsh restoration and was particularly supportive of creating an advisory group with a broad range of professionals to implement successful restoration projects. Thank you to all the RTW participants who leaned in to make this a valuable experience. Thank you to Susan Adamowicz for her review and contribution on SMARTeams. Thank you to Joseph Montesano for contributing site photos. Ilia Rochlin provided encouragement and valuable suggestions during the process. Conversations with participants including Adam Starke, Adrianna Zito-Livingston, Elizabeth Watson, Jim Feaga, Roger Wolfe, Wenley Ferguson, Joshua Moody, and Mitch Hartley and editing by Kristin France and Anna Bartlett enhanced the manuscript. Constructive comments from the WEM editor, Eric Wolanski, and 2 anonymous reviewers greatly improved the manuscript.

Author contributions All authors contributed to the paper conception and design. Figure 4 was created by Camilo Salazar. The first draft of the manuscript was written by Nicole Maher and all authors commented on and contributed to later versions of the manuscript.

Funding Support for the learning exchange described in this article was through a U.S. Department of the Interior (DOI) Hurricane Sandy Coastal Resiliency Competitive Grant Program (HSCR) administered by the National Fish and Wildlife Foundation (NFWF) to Suffolk County (NY): Wetland Restoration in Suffolk County (NY) project ID
43006. However, the grant did not cover the time of the coauthors to write this article. N. Maher is grateful for the generous support of the William E. \& Maude S. Pritchard Charitable Trust. Camilo Salazar's funding comes from The Water Quality Unit, Department of Economic Development and Planning, Suffolk County, Water Quality Unit, Department of Economic Development and Planning.

Data availability The final report and field trip notes from the learning exchange described here are available from the corresponding author and Suffolk County on request.

\section{Declarations}

Conflict of interest During the time of the learning exchange described in this manuscript, author, N. Maher, as an employee of The Nature Conservancy received support from Suffolk County (NY) as a sub-award from their U.S. Department of the Interior's (DOI) Hurricane Sandy Coastal Resiliency Competitive Grant Program (HSCR) administered by the National Fish and Wildlife Foundation (NFWF). Author, C. Salazar is an employee of Suffolk County (NY) and managed the execution of the NFWF grant that supported this learning exchange and the restoration projects implemented. Author, A. Fournier has no conflicts to disclose.

Consent for publication All authors read and approved the final manuscript.

Open Access This article is licensed under a Creative Commons Attribution 4.0 International License, which permits use, sharing, adaptation, distribution and reproduction in any medium or format, as long as you give appropriate credit to the original author(s) and the source, provide a link to the Creative Commons licence, and indicate if changes were made. The images or other third party material in this article are included in the article's Creative Commons licence, unless indicated otherwise in a credit line to the material. If material is not included in the article's Creative Commons licence and your intended use is not permitted by statutory regulation or exceeds the permitted use, you will need to obtain permission directly from the copyright holder. To view a copy of this licence, visit http://creativecommons.org/licenses/by/4.0/.

\section{References}

Adamowicz SC, Wilson G, Burdick DM, Ferguson W, Hopping R (2020) Farmers in the marsh: lessons from history and case studies for the future. Wetl Sci Pract 37(3):182-195

Babson AL, Bennett RO, Adamowicz SC, Stevens S (2020) Coastal impacts, recovery, and resilience post-hurricane sandy in the Northeastern US. Estuar Coasts 43(7):1603-1609

Basso GK, O'Brien K, Albino Hegeman M, and V. O’Neill V (2015) Status and trends of wetlands in the Long Island Sound Area: 130 year assessment. U.S. Department of the Interior, Fish and Wildlife Service, p 35 
Benvenuti B, Walsh J, O'Brien KM, Kovach AI (2018) Plasticity in nesting adaptations of a tidal marsh endemic bird. Ecol Evol 8:10780-10793. https://doi.org/10.1002/ece3. 4528

Burdick DM, Moore GE, Adamowicz SC, Wilson GM, Peter CR (2020) Mitigating the legacy effects of ditching in a New England salt marsh. Estuar Coasts 43:1672-1679. https:// doi.org/10.1007/s12237-019-00656-5

Cameron Engineering and Associates (CEA) (2015) Long Island tidal wetland trends analysis. Prepared for the New England Interstate Water Pollution Control Commission, p 207, http://www.dec.ny.gov/lands/5113.html

Dale PER, Hulsman K (1990) A critical-review of salt-marsh management methods for mosquito-control. Crit Rev Aquat Sci 3:281-311

Dale PER, Knight JM (2008) Wetlands and mosquitoes: a review. Wetl Ecol Manag 16:255-276. https://doi.org/10. 1007/s11273-008-9098-2

Dale PER, Knight JM (2012) Managing mosquitoes without destroying wetlands: an eastern Australian approach. Wetl Ecol Manag 20:233-242. https://doi.org/10.1007/s11273012-9262-6

Daniels SE, Walker GB (2001) Working through environmental conflict: the collaborative learning approach. Praeger Publishers, Westport

Dwyer L, Bassow A, Flynn C (no date) Hurricane Sandy Coastal Resiliency Competitive Grant Program. https://www.nfwf. org/programs/hurricane-sandy-coastal-resiliencycompetitive-grant-program Accessed 2 Feb 2021

Ferguson W (2016) A matter of millimeters: helping our salt marsh survive sea level rise. Tides Mag save Bay 48(1):10-11

Feurt, C (2008) Collaborative Learning Guide for Ecosystem Management. Wells National Estuarine Research Reserve. Wells, Maine, p 20. https://www.wellsreserve.org/sup/ downloads/collaborative_learning_guide.pdf Accessed May 2021

Field CR, Bayard TS, Gjerdrum C, Hill JM, Meiman S, Elphick CS (2017) High-resolution tide projections reveal extinction threshold in response to sea-level rise. Glob Change Biol 23(5):2058-2070

Hartley MJ, Weldon AJ (eds) (2020) Saltmarsh Sparrow Conservation Plan. Atlantic Coast Joint Venture, acjv.org/ saltmarshsparrowplan https://www.acjv.org/documents/ SALS_plan_final.pdf Accessed 2 Feb 2021

Hulsman K, Dale PER, Kay BH (1989) The runneling method of habitat modification-an environment-focused tool for salt-marsh mosquito management. J Am Mosq Control Assoc 5:226-234

Maher NP (2018) Saltmarsh Restoration Regional Technical Workgroup (RTW): Final Report. Submitted to Suffolk County Dept. Economic Development and Planning in support of Suffolk County's National Fish and Wildlife Foundation ("NFWF") Sandy resiliency grant: Coastal Resiliency via Integrated Wetland Management, p 22

Meredith WH, Saveikis DE, Stachecki CJ (1985) Guidelines for "open marsh water management" in Delaware's salt marshes-objectives, system designs, and installation procedures. Wetlands 5:119-133

Meredith WH and Lesser CR (2007) Open marsh water management in Delaware: 1979-2007. New Jersey mosquito control association. In: Proceedings 94th annual meeting, pp 55-69

New York State Energy Research and Development Authority (NYSERDA) (2018) Integrating SLAMM results and stakeholder priorities to define marsh adaptation strategies, NYSERDA Report Number 18-04. Prepared by Warren Pinnacle Consulting, Inc. Waitsfield VT. nyserda.ny.gov/ publications

Paolisso M, Prell C, Johnson KJ, Needelman B, Khan IMP, Hubacek K (2019) Enhancing socio-ecological resilience in coastal regions through collaborative science, knowledge exchange and social networks: a case study of the Deal Island Peninsula, USA. Socio Ecol Pract Res 1:109-123. https://doi.org/10.1007/s42532-019-00010-w

Rochlin I, James-Pirri MJ, Adamowicz SC, Wolfe RJ, Capotosto P, Dempsey ME, Iwanejko T, Ninivaggi DV (2012) Integrated Marsh Management (IMM): a new perspective on mosquito control and best management practices for salt marsh restoration. Wetl Ecol Manag 20:219-232. https:// doi.org/10.1007/s11273-012-9251-9

UN Environ. Prog. (2006) Marine and coastal ecosystems and human well-being: a synthesis report based on the findings of the millennium ecosystem assessment. UNEP, Nairobi, p 76

Wigand C, Ardito T, Chaffee C, Ferguson W, Paton S, Raposa K, Vandemoer C, Watson E (2015) A climate change adaptation strategy for management of coastal marsh systems. Estuar Coasts 40:682-693. https://doi.org/10.1007/ s12237-015-0003-y

Wolfe RJ (1996) Effects of open marsh water management on selected tidal marsh resources: a review. J Am Mosq Control Assoc 12:701-712

Wolfe RJ (2005) Open marsh water management: a review of system designs and installation guidelines for mosquito control and integration in wetland habitat management. New Jersey Mosquito Control Association. In: Proceedings ninety second annual meeting

Publisher's Note Springer Nature remains neutral with regard to jurisdictional claims in published maps and institutional affiliations. 